\title{
Intracytoplasmic azurophilic inclusions in prolymphocytes
}

\author{
Nicholas Mackrides ${ }^{1} \cdot$ Izidore S. Lossos $^{2} \cdot$ Francisco Vega $^{1,2}$
}

Received: 10 August 2018 / Revised: 19 September 2018 / Accepted: 26 September 2018 / Published online: 9 October 2018

(c) The Japanese Society of Hematology 2018

A 69-year-old male with a history of splenic marginal zone lymphoma (SMZL), treated with rituximab and bendamustine, presented with massive splenomegaly without lymphadenopathy or hepatomegaly. A prior bone marrow biopsy was involved by SMZL, with a clonal male karyotype; 46,XY,del(10)(q24) [2]/46,XY,-10,+mar[7]/46,XY[11]. CBC showed a WBC count of $99,000 / \mu \mathrm{L}$ due to marked lymphocytosis. The peripheral smear showed the majority of lymphoid cells were intermediate to large in size with partially open nuclear chromatin, prominent nucleoli and abundant cytoplasm containing azurophilic granular inclusions (Fig. 1). There were several inclusions in almost all lymphoid cells, distributed throughout the cytoplasm. Flow cytometry immunophenotyping confirmed these were monoclonal B-cells, 93\% of cellular events, positive for CD19, CD20, and CD11c, and negative for CD3, CD4, CD5, CD8, CD10, $\mathrm{CD} 23, \mathrm{CD} 25, \mathrm{CD} 56$ and CD103. Although the presence of granular inclusions was unexpected, the overall findings were consistent with prolymphocytic transformation of the previously diagnosed SMZL.

It is typical to categorize lymphoid cells with azurophilic cytoplasmic granules as large granular lymphocytes (LGLs), which usually represent cells of T or NK-cell origin with cytotoxic activity. In LGLs, these granules are composed of the cytotoxic proteins that are released during interactions with target cells. Few previous manuscripts have reported azurophilic granules in B-cell prolymphocytes. Robinson et al. [1] reported a case of B-cell prolymphocytic leukemia (B-PLL) with azurophilic granules in almost all prolymphocytes. Electron microscopy demonstrated variable numbers of electron dense, rectangular or rod-shaped inclusions which varied in

Francisco Vega

fvega@med.miami.edu

1 Division of Hematopathology, Department of Pathology, University of Miami, Sylvester Comprehensive Cancer Center, Miami, FL 33136, USA

2 Division of Hematology, Department of Medicine, University of Miami, Sylvester Comprehensive Cancer Center, Miami, FL, USA

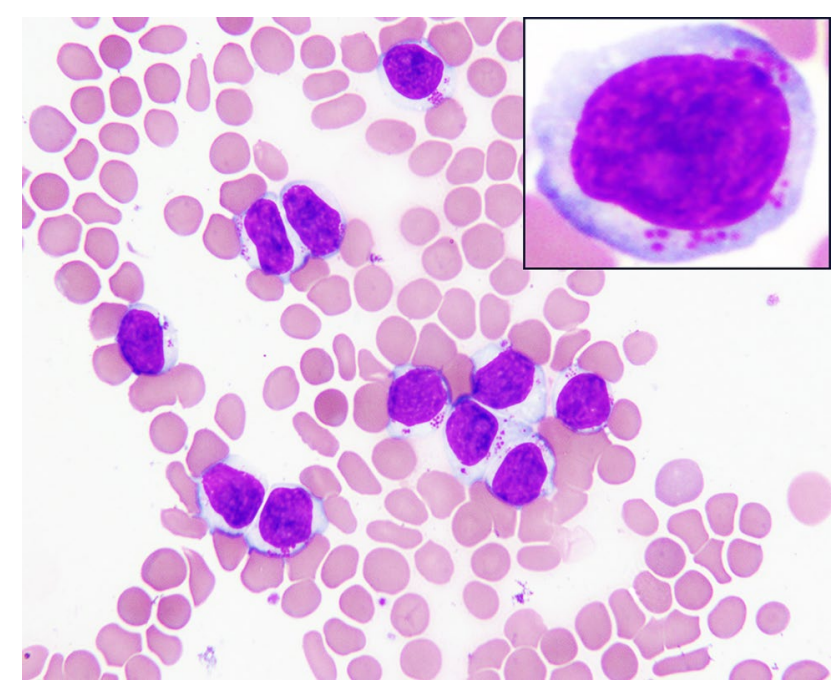

Fig. 1 Prolymphocytes most of which have azurophilic granular inclusions (Wright Giemsa $\times 500$ ). Inset, the magnification of a single prolymphocyte to highlight the cytoplasmic granules

size from 0.2 to 0.6 microns. Immunocytochemistry confirmed the inclusions were composed of immunoglobulin [1].

While rare cases of B-PLL with granular cytoplasmic inclusions have previously been reported, we believe the phenomenon is not well known, even among experienced hematologists and hematopathologists. Physicians should be aware of this rare presentation of B-cell prolymphocytes, and such findings can assist in diagnosis of these patients.

\section{Compliance with ethical standards}

Conflict of interest We do not have any conflict of interest to disclosure.

\section{Reference}

1. Robinson DS, Melo JV, Andrews C, Schey SA, Catovsky D. Intracytoplasmic inclusions in B prolymphocytic leukaemia: ultrastructural, cytochemical, and immunological studies. J Clin Pathol. 1985;38(8):897-903. 